\title{
Review Article \\ Key Success Factors and Future Perspective of Silicon-Based Solar Cells
}

\author{
S. Binetti, ${ }^{1}$ M. Acciarri, ${ }^{1}$ A. Le Donne, ${ }^{1}$ M. Morgano, ${ }^{1}$ and Y. Jestin ${ }^{2}$ \\ ${ }^{1}$ Milano-Bicocca Solar Energy Research Center (MIB-SOLAR), Department of Materials Science, \\ University of Milano-Bicocca, Via Cozzi 53, 20126 Milano, Italy \\ ${ }^{2}$ Centre for Materials and Microsystems, Fondazione Bruno Kessler, Via Sommarive 18, 38123 Trento, Italy
}

Correspondence should be addressed to S. Binetti; simona.binetti@unimib.it

Received 18 January 2013; Accepted 6 February 2013

Academic Editor: Sudhakar Shet

Copyright (C) 2013 S. Binetti et al. This is an open access article distributed under the Creative Commons Attribution License, which permits unrestricted use, distribution, and reproduction in any medium, provided the original work is properly cited.

\begin{abstract}
Today, after more than 70 years of continued progress on silicon technology, about $85 \%$ of cumulative installed photovolatic (PV) modules are based on crystalline silicon (c-Si). PV devices based on silicon are the most common solar cells currently being produced, and it is mainly due to silicon technology that the PV has grown by $40 \%$ per year over the last decade. An additional step in the silicon solar cell development is ongoing, and it is related to a further efficiency improvement through defect control, device optimization, surface modification, and nanotechnology approaches. This paper attempts to briefly review the most important advances and current technologies used to produce crystalline silicon solar devices and in the meantime the most challenging and promising strategies acting to increase the efficiency to cost/ratio of silicon solar cells. Eventually, the impact and the potentiality of using a nanotechnology approach in a silicon-based solar cell are also described.
\end{abstract}

\section{Introduction}

Photovoltaic (PV) devices based on silicon are the most common solar cells currently being produced, and it is mainly due to silicon technology that the PV has grown by $40 \%$ per year over the last decade. Cost, sustainability, and environmental issues are at the core of actual PV industry activities. Competitors other than silicon have emerged in the last ten years. Organic PV is a fast growing research topic with the first companies producing products for consumers. Apart from efficiency, different open problems of DSC and organic solar cells still remain, such as scaled-up module prototypes, solar efficiencies fall up to $5 \%$ in outdoor, low lifetime and durability (less than 1 year), and a lack of standardized stability data. All these considerations will make it very difficult for organic solar cells to be competitive with respect to silicon solar cells in the next decades.

In the frame of inorganic thin film, $\mathrm{Cu}(\mathrm{In}, \mathrm{Ga}) \mathrm{Se}_{2}$ (CIGS) solar cells are one of the most promising in terms of both efficiency record $(20.3 \%)$, nearly reaching the one of Si solar cell [1], and stability. Despite the promise of CIGS thin film and also of CdTe photovoltaic technologies with respect to reducing cost per watt of solar energy conversion, these approaches rely on elements that are either costly and/or rare in the earth's crust (e.g., In, $\mathrm{Ga}$, and $\mathrm{Te}$ ) or that present toxicity issues (e.g., Cd), thereby potentially limiting these technologies in terms of future cost reduction and production growth. The new material (CZTS) in which indium and gallium from CIGS are replaced by the readily available elements zinc and tin $[2,3]$ is far to be applied or to be on the market rapidly. Furthermore, thin film technology still remains a smaller (albeit growing) part of the overall PV production.

On the other hand, the silicon solar cells technological improvements resulted in the achievement of the $25 \%$ record efficiency on lab scale and of $22 \%$ in production [4], very close to the theoretical maximum efficiency for a single junction PV device of $31 \%$. This record is the latest step in more than 70 years history of silicon cell development. An additional step in the silicon solar cell development is ongoing, and it is related to further efficiency improvements through defect control, device optimization, surface modification, and nanotechnology approaches, these researches being aimed at increasing or at overcoming the classical efficiency limit. 
This paper firstly attempts to point out the most important advances and current technologies used to produce crystalline silicon solar devices and in the meantime the most challenging and promising strategies acting to increase the ratio between the efficiency and the cost of silicon solar cells. Furthermore, recent results of our group on silicon-based device are reported.

\section{Multicrystalline Silicon Solar Cells}

Within c-Si, multicrystalline-(mc-) Si technology is the more commonly used material. This trend is growing and mc$\mathrm{Si}$ modules will continue to retain a large portion of the market in the future. All this is strictly related to the fact that multicrystalline silicon is able to increase the ratio between efficiency and cost most effectively than monocrystalline one. Advanced mc-Si solar cells use new concepts for the technology of crystalline silicon in order to boost the efficiency of industrial cells and modules above $20 \%$, for example, by laser technologies, fine line metallization, and improved front and back contacts. Details on the processing techniques as well as the most important milestones and breakthroughs for mc-Si solar cells are reported in [5]. A better understanding of defects and their influence on mc solar cells properties has been having a very relevant role in reducing the gap in the efficiency with respect to monocrystalline one. Gettering and passivation procedures have been studied for many years and used effectively to increase the efficiency of mc-Si. In any case, considerable efforts are still needed to approach the theoretical efficiency limit in multicrystalline silicon solar cells due to higher defect content, especially grain boundaries (GBs) and dislocations known to be harmful for the final cell performances. Reducing this harmful effect could be achieved by controlling the crystal growth in order to produce large grains in preferred orientations in such a way that the resulting grain boundaries do not generate, or generate less, dislocations. Dislocations have been identified as one of the main killer defects in mc-Si. In order to further increase the efficiency of mc-Si solar cell, a still crucial point is to understand the properties of dislocation-related deep levels as well as possible effects of interaction of impurities with dislocations. As matter of fact, in spite of many years of investigations, many aspects related to the influence of impurities on the electrical activity of dislocations are still open. Its electrical activity arises from intrinsic structural disorder at dislocation cores [6] shallow defect bands due to longrange strain fields and extrinsic impurity decoration $[7,8]$. Nevertheless, it appears clear that dislocations do not have simple and regular influence on electrical properties of the material or on those of the devices.

All that considered, a lot of experimental and theoretical work should still be done also in this fundamental field. The control of defects density and the so-called defect engineering have become recently even more important, considering the potential of metallurgical grade silicon feedstock. During the Si feedstock crisis that started in 2005, the metallurgical purification routes taken by different companies (i.e., Dow Corning, Elkem, and others) attracted much attention due to the scalability and fast setup time for factories. Solar grade from metallurgical grade (MG) silicon of reduced purity is currently being explored with the goal to further reduce material cost. Besides the cost, many are the advantages of using metallurgical silicon. The investment cost for an industrial scale feedstock production plant is expected to be significantly reduced compared to the investment for a comparable production plant based on trichlorosilane technology. Likewise, the energy payback of a silicon solar cell, nowadays mainly affected by the energy used to purify and crystallize the base silicon, can be reduced to 1 year or less using MG-Si. But due to the higher concentrations of deleterious impurities in $\mathrm{MG}-\mathrm{Si}$, new approaches are necessary and have been developed to make cost-effective solar cells from low-cost, but impurity-rich, feedstock. Some approaches deal, for instance, with metal nanodefects engineering to recover minority carrier diffusion length in heavily contaminated materials by proper thermal annealing $[9,10]$ or with developing new gettering process. To this date, the phosphorus diffusion at high temperature is the best and well-known gettering process, due to the enhanced solubility of gettered species in the phosphorus diffused layer.

Despite the higher level of metal contaminations, many works report that similar solar efficiency to those obtained with electronic grade feedstock can be achieved [11].

Furthermore, MG or solar grade silicon generated by refining processes often contains a large amount of doping elements (i.e., boron and phosphorus). In order to use this silicon besides controlling the maximum concentrations of different metallic impurities, the research is focusing also on the maximum acceptable concentrations of the doping elements and its effect on material and cell parameters [12, 13] Recently, the Hall majority carrier mobility of p-type, compensated multicrystalline solar grade silicon wafers for solar cells in the temperature range 70-373 K has been investigated. In the range of interest for silicon solar cells (above room temperature), the trend in carrier mobility is similar for all samples, and the measured value for the sample with low compensation ratio $\left(R_{C}\right)$ and low doping density is comparable to the uncompensated references (Figure 1). With decreasing temperature below approximately $150 \mathrm{~K}$, the difference between samples with low $R_{C}$ and samples with high $R_{C}$ becomes higher [14].

The work carried out up to now seems to indicate that MG silicon can be used to produce effectively solar cells if impurities are below a well-defined limit indicated as solar grade specifications. In the case of higher impurities concentration, it is clear that the silicon supply could be much larger and or at lower cost or more sustainable. All these points can contribute to reduce the silicon solar cells cost. It is also clear that this material requires strong modification in crystallization process and in device realization, like new gettering or passivation process or postgrowth annealing step.

\section{Light Harvesting Approach: The Down-Shifting Process}

It is widely known that in a silicon solar cell a large portion of the energy loss can be ascribed to thermalization process. 


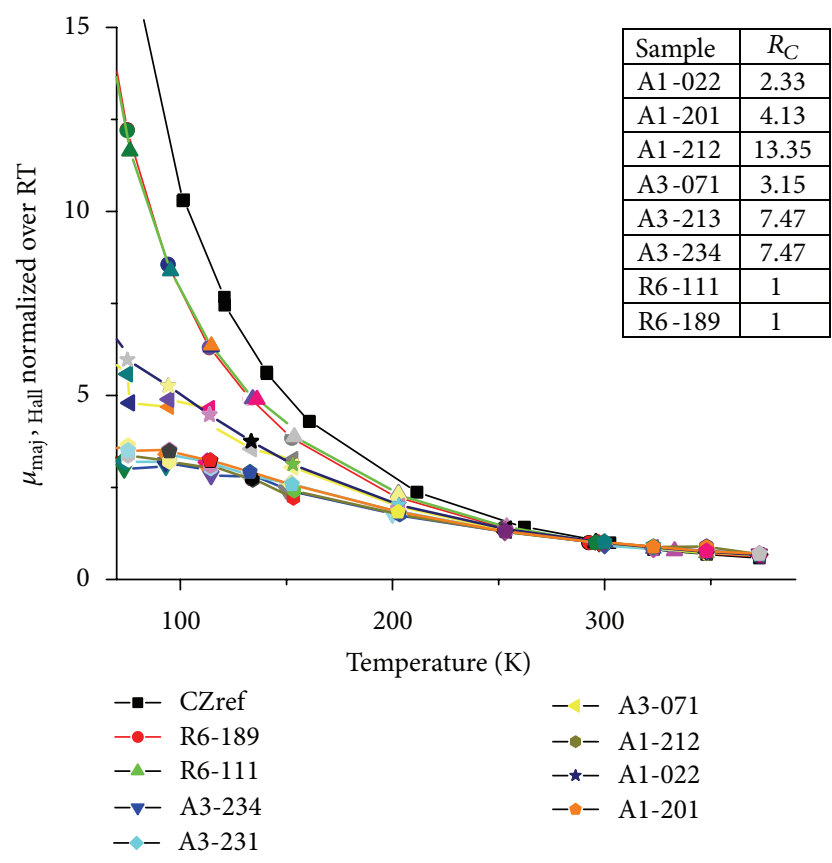

FIgURE 1: Temperature-dependent majority carrier mobility, $\mu_{\text {maj,Hall }}$, as measured by the Hall-effect setup, normalized values (ratio of the measured value at the given temperature over the measured value at room temperature). The compensation ratios $\left(R_{C}\right)$ of the different samples are reported in the table on the right. Adapted from [14].

A modification of the incident solar spectrum which allows a better exploitation of the high energy region is therefore expected to increase the efficiency of such a single junction cell. A possible approach to modify the high energy side of the solar spectrum is down-shifting [15]. In this process, one low energy photon is created by one high energy photon absorbed into a proper molecular system emitting around the maximum quantum efficiency value of the photovoltaic (PV) device. Molecular systems strongly absorbing in the high energy range and showing a consistent Stokes shift of their emission towards the region of the maximum conversion efficiency of the PV device are good candidates for downshifting of the absorbed light. Rare-earth organic complexes constituted by a conjugated molecule acting as antenna and by an emitting lanthanide ion are good candidates as downshifter (DSs). They possess also the separation between the absorption and the emission bands required to obtain large Stokes shift and to avoid self-absorption losses. In recent years, we have been working on inorganic DSs complexes to realize down-shifting of photons with wavelength lower than $400 \mathrm{~nm}$ without introducing strong modifications of the industrial process leading to the fabrication of the PV modules. Organolanthanide-based DSs have been included in polymeric layers suitable as PV modules encapsulating matrix. Relative enhancements of the total delivered power up to $2.9 \%$ have been reported for Si solar cells coated with $1 \mu \mathrm{m}$ thick $\mathrm{Eu}(\mathrm{tfc})_{3} / 4,4^{\prime}$ bis(diethylamino) benzophenonedoped EVA [16] (see Figure 2).

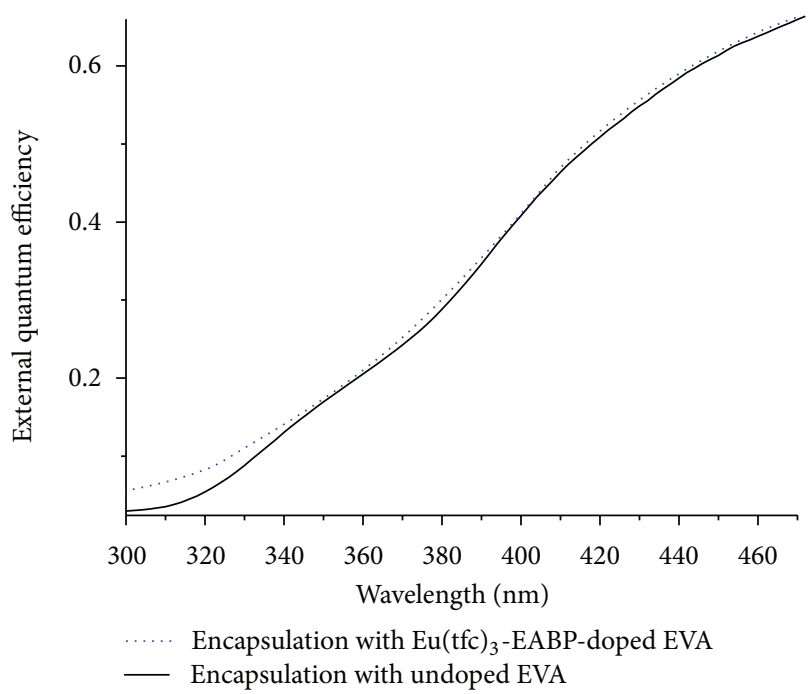

FIgURE 2: EQE measurements recorded on c-Si-based test modules encapsulated with undoped (solid line) and $\mathrm{Eu}(\mathrm{tfc})_{3} /$ $4,4^{\prime}$ bis(diethylamino) benzophenone-(Eu(tfc) $)_{3}$-EABP-) doped EVA (dots). The only down-shifting spectral region has been showed for better clarity.

Beside organolanthanide complexes, quantum dots (QDs) materials are also promising solution for the modification of the high energy side of the solar spectrum [17], considering also their higher stability. Due to the reduced dimensionality, QDs exhibit quantization of their electronic energy levels, with a consequent blue-shift of the optical absorption edge. The QDs electronic energy levels and optical absorption being dependent on their size, the effective bandgap can be easily tuned for solar spectrum modification purposes. In the last few years, QDs systems showing the potentialities for effective solar spectrum modification have been investigated $[18,19]$. However, most of them contain toxic elements such as $\mathrm{Cd}, \mathrm{Pb}$, and $\mathrm{Se}$ (e.g., CdSe, PbSe, and $\mathrm{PbS} \mathrm{QDs})$. In order to focus the attention on nontoxic systems, we have tested ZnS nanoparticles (NPs) [20], already known as low cost, largely available luminescent materials [21]. $\mathrm{ZnS}: \mathrm{Mn}^{2+}$ NPs have been prepared by wet chemical synthesis, a quite inexpensive and scalable method matching the requirements for photovoltaics. In particular, the $\mathrm{Mn}^{2+}$ related emission centered at $597 \mathrm{~nm}$ observed for $\mathrm{ZnS}: \mathrm{Mn}^{2+}$ NPs size higher than $3.5 \mathrm{~nm}$ is really close to the maximum quantum efficiency of crystalline silicon-(c-Si-) based solar cells. The effect on the EQE of the deposition of $\mathrm{ZnS}: \mathrm{Mn}^{2+}$ NPs on a commercial c-Si solar cell is showed in Figure 3, where the relative enhancement of the EQE is reported. The incident UV radiation is absorbed by the $\mathrm{ZnS}: \mathrm{Mn}^{2+} \mathrm{NPs}$, generating photons emitted at longer wavelenghts where $\mathrm{Si}$ is more efficient. A sharp peak of the relative EQE enhancement $(\sim 6 \%)$ is present around $350 \mathrm{~nm}$ which is consistent with the absorption edge of the QDs (shown in the inset in Figure 3). 


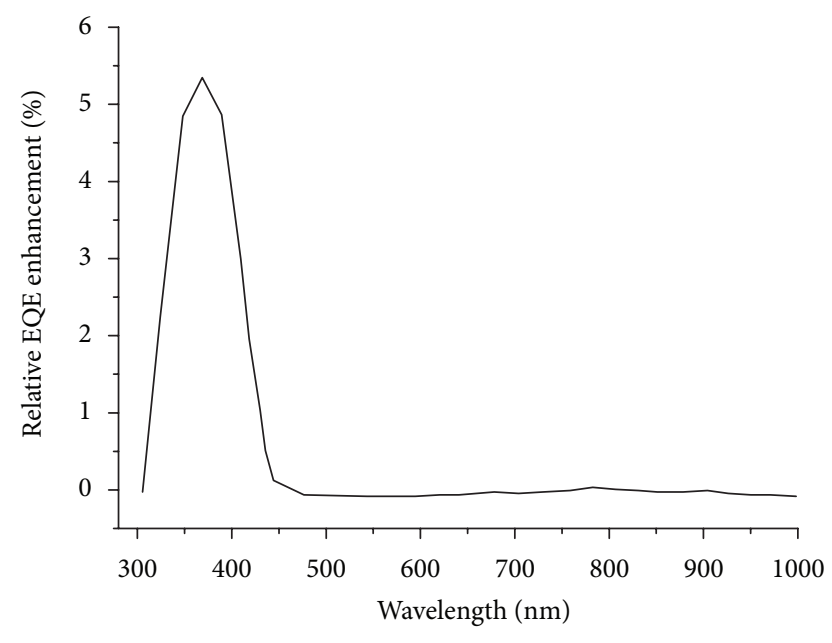

FIGURE 3: Relative EQE enhancement for a commercial monocrystalline Si solar cell after the deposition of $\mathrm{ZnS}: \mathrm{Mn}^{2+} \mathrm{NPs}$.

\section{Nanotechnology Approach}

Among the different ways of exploiting nanotechnologies and typical nanoscale concepts, the band gap engineering of a silicon-based material is the most attractive. silicon-rich oxide (SRO) and silicon-rich nitride (SRN) are the materials currently object of research for the realization of an all-silicon tandem solar cell. This material consists of nonstoichiometric silicon oxide or silicon nitride layers that, upon annealing at high temperature, can form quantum dots (QDs) after precipitation of the excess silicon. The quantum confinement effect of carriers induced by this nanostructuration might allow the optical band gap of the SRO to be tuned, increasing it from the bulk silicon value, allowing the realization of all silicon based tandem solar cells $[22,23]$. Moreover, there are no concerns about the toxicity of SRO or SRN, they are already widely available and widespread, and their realization process is fully compatible with the microelectronic industry and so with a large scale production.

Prototype devices have been already realized [24], but the efficiency obtained is still very low (less than $0.1 \%$ ). Of the main issues to be still solved, and probably the research bottlenecks, are the doping of such nanostructures and the electrical transport processes [25].

It is clear that the extraction of photogenerated current is crucial, and it is made even more difficult by the presence of the insulating materials embedding the nanodots. In order to understand the transport mechanism in the configuration of QDs-based solar cell (i.e., from top to bottom), we performed $I V$ scans on supposedly nanodoped as well as on intrinsic SRO samples.

Plasma-enhanced chemical vapor deposition (PECVD) was used to deposit 10 bilayers (nominal thickness $1.5 \mathrm{~nm}$ of each layer) of alternative layer of $\mathrm{Si}$-rich $\mathrm{SiO}_{2}(\mathrm{SRO})$ and $\mathrm{SiO}_{2}$ on $<100>10 \mathrm{ohm} \mathrm{cm}$ p-type silicon wafer. Technical details are in [26].

All the samples have been annealed at $1050^{\circ} \mathrm{C}$ for one hour to nucleate the dots and to drive excess hydrogen away. To

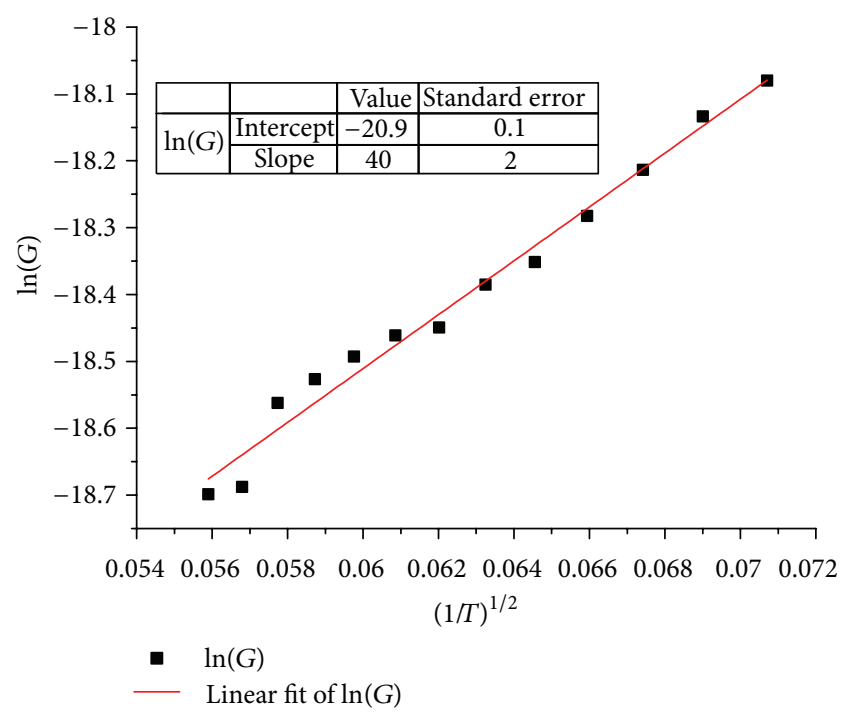

FIgURE 4: Plot of the log of the conductance versus the inverse square root of the temperature used for the fit demonstrating percolation mechanism.

identify the transport mechanism, we performed $I / V$ scans at different temperatures. By fitting with a straight line the region around the origin $( \pm 0.5 \mathrm{~V}$, where the shape of the $I V$ can be linearly approximated), we can obtain the temperature dependence of the conductance $(G)$ versus the temperature. As can be seen in Figure 4, the values show a pretty good agreement with a linear relationship between the logarithm of the conductance and the inverse square root of the temperature, compatible with a hopping-percolation model as in [27], not completely suitable for a solar cell applications.

On the same samples, a feeble effect of light has been observed. From Figure 5, we can see that the conduction is diode-like in the dark but symmetric under illumination. This behavior can be explained by the generation of electron-hole pairs promoted by the photons. When there is no light, the sample acts as an MIS diode with an insulator layer made by the SRO even if this layer does not act as a full $200 \mathrm{~nm}$ thick layer of oxide. Nanostructuration and its composition play a crucial role in reducing the effective thickness of this layer, since a $200 \mathrm{~nm}$ thick stoichiometric layer of $\mathrm{SiO}_{2}$ would prevent the conduction at this voltage. In this condition, the nanodots probably act as filled traps where carriers can have a good mobility and they do not participate at the conduction. When light is on, the dots might act as electron-hole couples generator (as they are intrinsic) and the conduction can be symmetric in the two directions.

A requirement for a tandem solar cell is the presence of a junction, and another crucial point is the doping of the $\mathrm{Si}$ QDs material. Although the doping mechanism is not clearly understood, homo- and heterojunction devices have been fabricated based on Si QD [24]. In any case, a strong improvement in understanding carrier transport and in doping mechanism is still needed. 


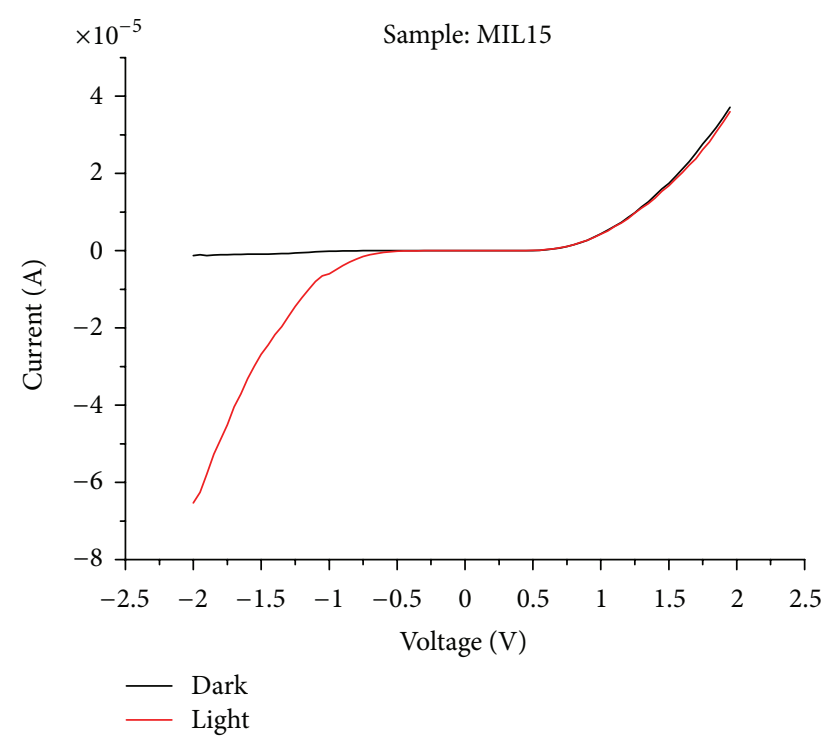

FIgURE 5: $I / V$ scans of the samples in dark and under illumination.

\section{Conclusions}

Although new materials are coming and opening new outlook on the future of solar energy, silicon should be the leading material also in the next future. If we consider its peculiar properties and unique advantages: availability, no toxicity, long lifetime, and sustainability, no competitors are on the market. Development, innovation, and new devices concepts in silicon solar cells are taking place to bring down the cost of solar technologies and make them even more cost competitive with conventional sources. The reduction of costper-Watt towards grid parity and the grow of global installed power towards the Terawatt level can be achieved by silicon solar cells. However, an intense R\&D activity is still needed to reach the target of a $40 \%$ efficiency silicon-based 9 solar cells will not be a dream.

\section{Acknowledgment}

The authors would like to thank Professor Lorenzo Pavesi for many fruitful discussions.

\section{References}

[1] P. Jackson, D. Hariskos, E. Lotter et al., "New world record efficiency for $\mathrm{Cu}(\mathrm{In}, \mathrm{Ga}) \mathrm{Se}_{2}$ thin-film solar cells beyond 20\%," Progress in Photovoltaics: Research and Application, vol. 19, no. 7, pp. 894-897, 2011.

[2] T. K. Todorov, K. B. Reuter, and D. B. Mitziet, "High-efficiency solar cell with earth-abundant liquid-processed absorber," Advanced Materials, vol. 22, no. 20, pp. E156-E159, 2010.

[3] H. Katagiri, K. Jimbo, S. Yamada et al., "Enhanced conversion efficiencies of $\mathrm{Cu}_{2} \mathrm{ZnSnS}_{4}$-based thin film solar cells by using preferential etching technique," Applied Physics Express, vol. 1, no. 4, 2008.

[4] M. A. Green, K. Emery, Y. Hishikawa, W. Warta, and E. D. Dunlop, "Solar cell efficiency tables (version 39)," Progress in
Photovoltaics: Research and Applications, vol. 20, no. 2, pp. 1220, 2012.

[5] R. Kopecek and M. McCann, "Multicrystalline silicon solar cells: standard processes and trends," in Handbook of Silicon Photonics, CRC Press, Taylor \& Francis Group, 2013.

[6] A. Castaldini, D. Cavalcoli, A. Cavallini, and S. Pizzini, "Experimental evidence of dislocation related shallow states in p-type Si," Physical Review Letters, vol. 95, no. 7, Article ID 076401, pp. $1-4,2005$.

[7] M. Kittler, C. Ulhaq-Bouillet, and V. Higgs, "Influence of copper contamination on recombination activity of misfit dislocations in $\mathrm{SiGe} / \mathrm{Si}$ epilayers: temperature dependence of activity as a marker characterizing the contamination level," Journal of Applied Physics, vol. 78, no. 7, pp. 4573-4583, 1995.

[8] S. Acerboni, S. Pizzini, S. Binetti, M. Acciarri, and B. Pichaud, "Effect of oxygen aggregation processes on the recombining activity of $60^{\circ}$ dislocations in Czochralski grown silicon," Journal of Applied Physics, vol. 76, no. 5, pp. 2703-2710, 1994.

[9] M. D. Pickett and T. Buonassisi, "Iron point defect reduction in multicrystalline silicon solar cells," Applied Physics Letters, vol. 92, no. 12, Article ID 122103, 2008.

[10] J. Hofstetter, D. P. Fenning, J. F. Leliefvre, C. del Canizo, and T. Buonassisi, "Engineering metal precipitate size distributions to enhance gettering in multicrystalline silicon," Physica Status Solidi A, vol. 209, no. 10, pp. 1861-1865, 2012.

[11] G. Coletti, P. C. Bronsveld, G. Hahn et al., "Impact of metal contamination in silicon solar cells," Advanced Functional Materials, vol. 21, no. 5, pp. 879-890, 2011.

[12] J. Libal, S. Novaglia, M. Acciarri et al., "Effect of compensation and of metallic impurities on the electrical properties of Czgrown solar grade silicon," Journal of Applied Physics, vol. 104, no. 10, Article ID 104507, 2008.

[13] J. Veirman, S. Dubois, N. Enjalbert, J. P. Garandet1, and M. Lemiti, "Electronic properties of highly-doped and compensated solar-grade silicon wafers and solar cells," Journal of Applied Physics, vol. 109, no. 10, Article ID 103711, 2011.

[14] C. Modanese, M. Acciarri, S. Binetti, A. Søiland, M. Acciarri, and S. Binetti, "Temperature-dependent Hall-effect measurements of p-type multicrystalline compensated solar grade silicon," Progress in Photovoltaics: Research and Applications, 2012.

[15] E. Klampaftis, D. Ross, K. R. McIntosh, and B. S. Richards, "Enhancing the performance of solar cells via luminescent down-shifting of the incident spectrum: a review," Solar Energy Materials \& Solar Cells, vol. 93, no. 8, pp. 1182-1194, 2009.

[16] A. Le Donne, M. Dilda, M. Crippa, M. Acciarri, and S. Binetti, "Rare earth organic complexes as down-shifters to improve Sibased solar cell efficiency," Optical Material, vol. 33, no. 7, pp. 1012-1014, 2011.

[17] C. Y. Huang, D. Y. Wang, C. H. Wang et al., "Efficient light harvesting by photon downconversion and light trapping in hybrid ZnS nanoparticles/Si nanotips solar cells," ACS Nano, vol. 4, no. 10, pp. 5849-5854, 2010.

[18] A. J. Nozik, "Quantum dot solar cells," Physica E, vol. 14, pp. 115120, 2002.

[19] V. I. Klimov, S. A. Ivanov, J. Nanda et al., "Single-exciton optical gain in semiconductor nanocrystals," Nature, vol. 447, no. 7143, pp. 441-446, 2007.

[20] A. Le Donne, S. K. Jana, S. Banerjee, S. Basu, and S. Binetti, "Optimized luminescence properties of Mn doped $\mathrm{ZnS}$ nanoparticles for photovoltaic applications," Journal of Applied Physics, vol. 113, no. 1, Article ID 014903, 5 pages, 2013. 
[21] J. Cao, J. Yang, Y. Zhang et al., “Optimized doping concentration of manganese in zinc sulfide nanoparticles for yellow-orange light emission," Journal of Alloys and Compounds, vol. 486, no. 1-2, pp. 890-894, 2009.

[22] E. C. Cho, S. Park, X. Hao et al., "Silicon quantum dot/crystalline silicon solar cells," Nanotechnology, vol. 19, no. 24, Article ID 245201, 2008.

[23] D. Di, I. Perez-Wur, G. Conibeer, and M. A. Green, "Formation and photoluminescence of $\mathrm{Si}$ quantum dots in $\mathrm{SiO}_{2} / \mathrm{Si}_{3} \mathrm{~N}_{4}$ hybrid matrix for all-Si tandem solar cells," Solar Energy Materials and Solar Cells, vol. 94, no. 12, pp. 2238-2243, 2010.

[24] I. Perez-Wurfl, L. Ma, D. Lin, X. Hao, M. A. Green, and G. Conibeer, "Silicon nanocrystals in an oxide matrix for thin film solar cells with $492 \mathrm{mV}$ open circuit voltage," Solar Energy Materials and Solar Cells, vol. 100, pp. 65-68, 2012.

[25] M. Morgano, I. Perez-Wurfl, and S. Binetti, "Nanostructured silicon-based films for photovoltaics: recent progresses and perspectives," Science of Advanced Materials, vol. 3, no. 3, pp. 388-400, 2011.

[26] M. Wang, A. Anopchenko, A. Marconi et al., "Light emitting devices based on nanocrystalline-silicon multilayer structure," Physica E, vol. 41, no. 6, pp. 912-915, 2009.

[27] E. Šimánek, "The temperature dependence of the electrical resistivity of granular metals," Solid State Communications, vol. 40, no. 11, pp. 1021-1023, 1981. 

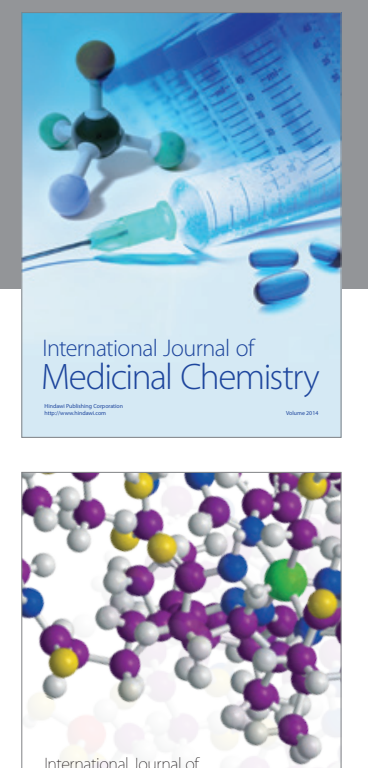

\section{Carbohydrate} Chemistry

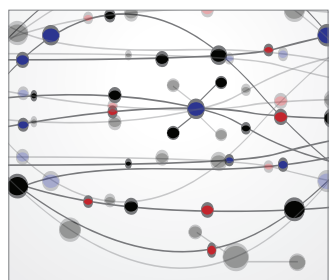

The Scientific World Journal
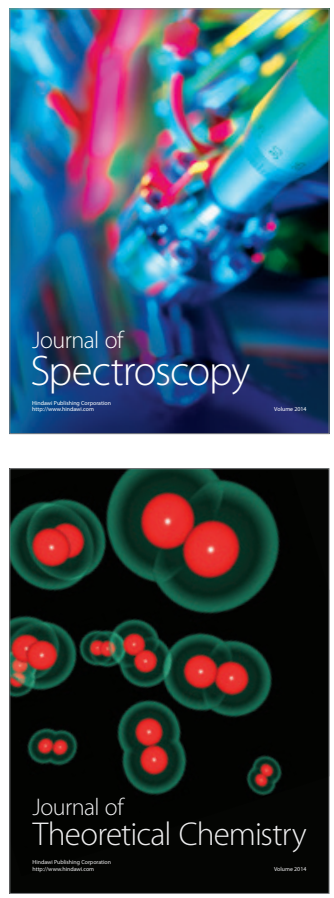
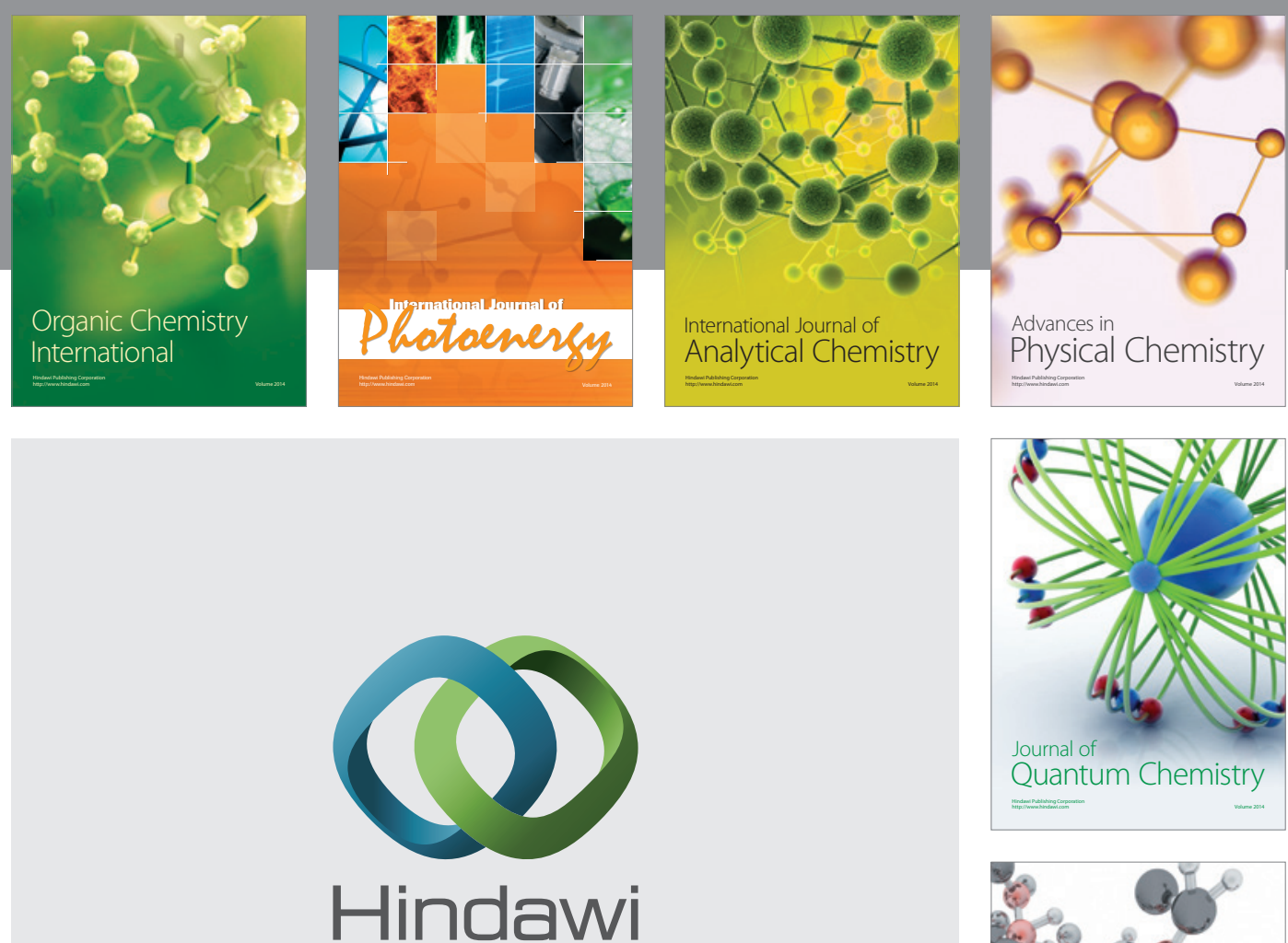

Submit your manuscripts at

http://www.hindawi.com

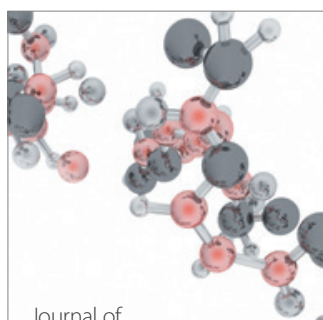

Analytical Methods

in Chemistry

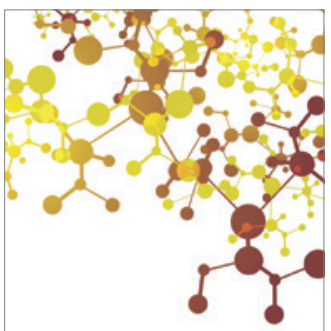

Journal of

Applied Chemistry

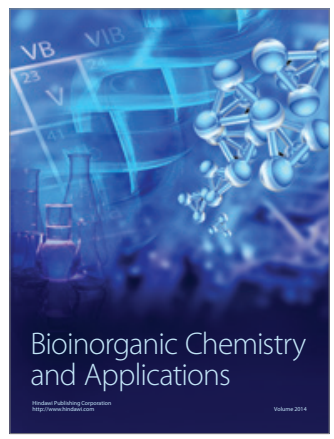

Inorganic Chemistry
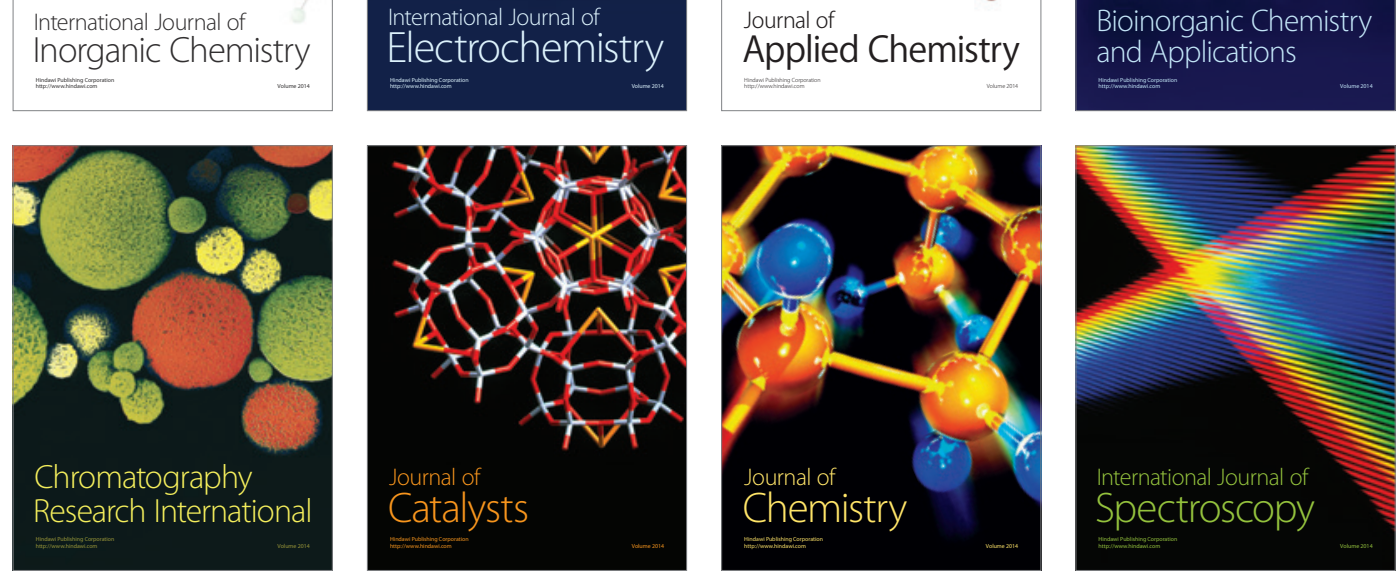